\title{
Associations of retinol-binding protein 4 with oxidative stress, inflammatory markers, and metabolic syndrome in a middle-aged and elderly Chinese population
}

Yan Liu ${ }^{1,2+}$, Duan Wang ${ }^{2 \dagger}$, Di Li ${ }^{1,2}$, Ruifang Sun ${ }^{1,2}$ and Min Xia ${ }^{1,2^{*}}$

\begin{abstract}
Background: Retinol-binding protein 4 (RBP4), a novel adipokine secreted by adipocytes and the liver, has elevated levels in type 2 diabetes mellitus (T2DM). However, its association with human metabolic diseases remains controversial. The present study was designed to investigate the associations of plasma RBP4 levels with oxidative stress, inflammatory markers, and metabolic syndrome (MetS) in a Chinese population.

Method: We evaluated plasma RBP4 levels in a cross-sectional sample of 1748 Chinese men and women aged 50 to 70 years in Guangzhou using an in-house developed and validated sandwich ELISA. Plasma glucose, insulin, lipid profile, serum adiponectin, adipocyte fatty acid-binding protein (A-FABP), 8-iso-prostaglandin F2a (8-iso PGF2a), 13-(S)-hydroxyoctadecadienoic acid (13-HODE), high-sensitivity C-reactive protein (hsCRP), interleukin 6 (IL6), monocyte chemotactic protein 1 (MCP1) and tumor necrosis factor a (TNFa) were all measured. MetS was defined according to the updated National Cholesterol Education Program Adult Treatment Panel III criteria for Asian Americans.

Results: Circulating RBP4 levels were positively correlated with A-FABP $(r=0.104, P<0.001)$, 8-iso PGF2a $(0.236$, $P<0.001)$, and $13-\mathrm{HODE}(0.204, P<0.001)$ and were inversely correlated with $\mathrm{HDL}$ cholesterol $(r=-0.072, P=0.004)$. After multivariable adjustment, the RBP4 levels were strongly associated with MetS and its components. The ORs $(95 \% \mathrm{Cls})$ for the comparisons of the extreme quartiles of RBP4 were $3.46(2.87,4.42)$ for MetS, $5.92(4.47,8.02)$ for hypertriglyceridemia, $1.42(1.11,1.68)$ for reduced $\mathrm{HDL}$ cholesterol, $1.87(1.48,2.36)$ for central obesity and 2.74 $(2.15,3.36)$ for hyperglycemia (all $P<0.001)$. When we further controlled for adipokines, markers of oxidative stress and proinflammatory response, the association of RBP4 with central obesity was abolished but not the association with other MetS components.
\end{abstract}

Conclusions: Plasma RBP4 levels are associated with an adverse profile of oxidative stress and inflammatory markers and an increased risk of MetS in this Chinese population. These associations are independent of conventional risk factors.

Keywords: RBP4, Oxidative stress, Inflammatory markers, Diabetes mellitus

\footnotetext{
*Correspondence: xiamin@mail.sysu.edu.cn

${ }^{\dagger}$ Equal contributors

${ }^{1}$ Guangdong Provincial Key Laboratory of Food, Nutrition and Health, Guangzhou, P.R. China

${ }^{2}$ Department of Nutrition, School of Public Health, Sun Yat-sen University (Northern Campus), Guangzhou, Guangdong Province 510080, P.R. China
} 


\section{Introduction}

Metabolic syndrome (MetS) is a clustering of multiple metabolic abnormalities, including central obesity, dyslipidemia, elevated blood pressure, hyperglycemia and insulin resistance. MetS plays an important role in the origin of cardiometabolic diseases, including cardiovascular disease (CVD) and type 2 diabetes mellitus [1-3]. Multiple mechanisms may contribute to MetS development, including an abnormal production of adipocyte- secreted proteins (adipocytokines), aberrant oxidative stress and dysregulated proinflammatory responses in tissues such as the muscle and liver [4-7]. Therefore, it is of vital importance to identify key risk factors for the early diagnosis and intervention of metabolic diseases.

Retinol-binding protein 4 (RBP4), mainly secreted by adipocytes and the liver, was originally known as the specific carrier of retinol in circulation [8]. Recent studies demonstrated that RBP4 levels were increased in obese and insulin-resistant humans and mouse models; additionally, a genetic or pharmacologic elevation of serum RBP4 causes insulin resistance in normal mice [9-11]. Although many studies show strong correlations of serum RBP4 levels with the severity of insulin resistance and obesity and with certain components of MetS, including hypertension [12], dyslipidemia [12,13], waist/hip ratio [13], cardiovascular disease $[14,15]$, and intra-abdominal fat mass [16], others do not demonstrate these correlations [17-19]. These inconsistencies may result from differences in age, ethnicity, population size, and the methodological techniques used [20]. Hence, it has yet to be established whether RBP4 may serve as a risk marker for insulin resistance and type 2 diabetes and to what extent it is associated with MetS.

Therefore, we examined the association between RBP4 and MetS risk among a middle-aged and elderly Chinese population. We focused on the correlation of RBP4 with oxidative stress and inflammatory factors, both of which are established or proposed risk factors for metabolic disorders.

\section{Methods}

\section{Study participants}

The study population consisted of individuals who underwent the Nutrition and Health of Aging Populations in South China study, which investigated the associations of dietary and genetic factors, as well as their interactions, with aging-related chronic diseases. From March 2008 to March 2009, 2289 participants aged 50-70 years were recruited from Guangzhou if they had been residents in their respective cities for 10 years. For this study, participants were excluded if one or more of the following criteria were met: younger than 50 years old; had a history of cancer, diabetes, CVD, or stroke; or had missing data on one component of the MetS diagnostic. The study protocol was approved by the Institutional Review Board of the Sun Yat-sen University, and written informed consent was obtained from all participants.

\section{Data collection}

Baseline data were collected by trained interviewers via semi-structured questionnaires during face-to-face interviews. The questionnaire was designed based on the pilot surveys among this population. Information on sociodemographic factors, health status, and lifestyle practices (including dietary factors and physical activity) was included in the questionnaire. Standing height, body weight, and waist circumference were measured with the participants in light indoor clothing and without shoes. Body mass index was calculated as weight in kilograms divided by height in meters squared. Two researchers independently entered the baseline data from the questionnaires, and the data were further checked by a third researcher when differences were found. All of the subjects were examined in the morning after an overnight fast.

\section{Laboratory measurements}

Overnight fasting blood samples were collected in tubes containing liquid EDTA, centrifuged at $4^{\circ} \mathrm{C}$, and stored at $-80^{\circ} \mathrm{C}$ until analysis. Total blood cholesterol, highdensity lipoprotein (HDL) cholesterol, triglycerides and glucose were measured enzymatically on a Hitachi 7180 Biochemistry Automatic Analyzer (Hitachi, Japan) using a commercial assay kit (Wako Pure Chemical Industries, Osaka, Japan). Low-density lipoprotein (LDL) cholesterol was subsequently calculated using the Friedewald formula [21]. Plasma insulin concentrations were measured by a radioimmunoassay (Roche, Indianapolis, IN) that has less than $0.2 \%$ cross-reactivity with proinsulin. A homeostasis model assessment of insulin resistance (HOMA-IR) was calculated as fasting insulin (in $1 \mathrm{IU} / \mathrm{mL}$ ) $\times$ fasting glucose (in $\mathrm{mmol} / \mathrm{L}$ )/22.5. Serum A-FABP concentrations were measured using an enzyme-linked immunosorbent assay (Cayman, Ann Arbor, MI), and the intra- and interassay CVs were $3.3-7.1 \%$ and $2.1-5.7 \%$, respectively.

The serum RBP4 concentrations were measured using an enzyme-linked immunosorbent assay (AdipoGen, Seoul, Korea), and the intra- and interassay CVs were $1.92-3.68 \%$ and $6.57-8.59 \%$, respectively. Serum adiponectin concentrations were measured using an enzyme-linked immunosorbent assay (AdipoGen, Seoul, Korea), and the intra- and interassay CVs were $4.1-5.9 \%$ and $3.7-6.3 \%$, respectively. Plasma RBP4 levels were measured in duplicate in plasma aliquots that had undergone 1 or 2 freeze-thaw cycles using a competitive enzyme-linked immunosorbent assay (ELISA) according to the manufacturer's instructions with purified human RBP4 standards (Adipogen, Inc.). The ELISA samples were run in duplicate. The coefficient of variation for interassay replicate samples was less than $7 \%$. 
The assay system was subsequently cross-validated by a Western blot analysis. The intraassay coefficient of variation was $1.8-7.6 \%$, and that of the interassay was $3.7-8.8 \%$. Plasma 8 -iso PGF2 $\alpha$ levels were quantitatively determined using an ELISA kit purchased from Enzo Life Sciences International (Plymouth Meeting, PA, USA). The assay sensitivity was $16.3 \mathrm{pg} / \mathrm{ml}$ (range $6.1-100,000 \mathrm{pg} / \mathrm{ml}$ ). The intraassay coefficient of variation was $4.4-11 \%$, and that of the interassay was $5.0-$ $11 \%$. Plasma 13-HODE concentrations were measured using a colorimetric competitive enzyme immunoassay kit (Enzo Life Sciences International). The assay sensitivity was $1.6 \mathrm{pmol} / \mathrm{ml}$ (range $0.7-100 \mathrm{pmol} / \mathrm{ml}$ ). The intraassay coefficient of variation was $6.4-7.3 \%$, and that of the interassay was $5.4-11.3 \%$.

Plasma CRP was measured using a particle-enhanced immunoturbidimetric assay (Ultrasensitive CRP kit, CRM diagnostic systems, Spain) with microparticles coated with anti-human CRP antibodies. The precision of the method in the cut-off value of decision $(1.8-2 \mu \mathrm{g} / \mathrm{ml})$ is less than $5.5 \%$. The serum levels of interleukin 6 (IL6), monocyte chemotactic protein 1 (MCP1), and tumor necrosis factor alpha (TNF $\alpha$ ) were measured using a MILLIPLEX ${ }^{\mathrm{TM}}$ Human Cytokine/Chemokine panel (Millipore, Billerica, MA). The intra- and interassay coefficients of variation were 8.1 and 11.6\% for IL6, 6.1 and 12.0\% for MCP1, and 10.5 and 15.9\% for TNF $\alpha$, respectively.

\section{Definition of MetS}

MetS was defined using the updated National Cholesterol Education Program/Adult Treatment Panel III criteria for Asian Americans as having $\geq 3$ of the following components: waist circumference $\geq 90 \mathrm{~cm}$ for men or $\geq 80 \mathrm{~cm}$ for women; triglycerides (TG) $\geq 1.7 \mathrm{mmol} / \mathrm{L}$; high-density lipoprotein (HDL) cholesterol $<1.03 \mathrm{mmol} / \mathrm{L}$ for men or $<1.30 \mathrm{mmol} / \mathrm{L}$ for women; blood pressure $\geq 130$ / $85 \mathrm{mmHg}$ or current use of antihypertensive medications; or fasting glucose $\geq 5.6 \mathrm{mmol} / \mathrm{L}$ [22].

\section{Statistical analysis}

The normally distributed data were expressed as the means $\pm \mathrm{SD}$, whereas variables with a skewed distribution were reported as the median (interquartile range) and $\log$ transformed to approximate normality before analysis. The categorical variables were represented by frequency and percentage. An analysis of covariance for the continuous variables and a multivariate logistic regression analysis for the categorical variables were applied for the comparison according to the RBP4 quartiles. An analysis of covariance was used to compare the RBP4 levels between genders and geographic locations. Correlation coefficients between RBP4 and metabolic features were calculated by a partial correlation analysis on ranks (Spearman correlation). The plasma RBP4 levels were depicted according to the number of MetS components using a linear regression model. Multivariate logistic regression models were used to estimate the odds ratios (ORs) for MetS and its components. Potential confounding variables, including age, gender, smoking, alcohol drinking, physical activity, educational level, self-reported CVD, family history of diabetes and CVD, CRP, adiponectin, homeostatic model assessment of insulin resistance (HOMA-IR), and body mass index (BMI), were controlled for in the regression models. The data management and statistical analyses were performed with SPSS 16.0 for Windows (SPSS Inc., Chicago, USA). A $P<0.05$ was considered statistically significant.

\section{Results}

A total of 1748 individuals (men and women) were included in this study. The characteristics of the study population according to the quartiles of plasma RBP4 concentrations are summarized in Table 1. Because no significant differences by sex were observed, men and women were analyzed together. There were significant associations between plasma RBP4 concentrations and BMI and waist circumference: the participants in the highest quartile of RBP4 had a higher BMI and waist circumference than those in the lower quartiles of RBP4, after adjustment for age and sex $(P<0.001)$. However, no significant associations were observed between RBP4 and current drinking or smoking status.

There were significant correlations between plasma RBP4 and plasma fasting glucose $(P=0.018)$ and HOMAIR $(P=0.048)$, but no significant associations with insulin were found $(P=0.054$, Table 2$)$. The participants in the highest quartile of plasma RBP4 levels had higher plasma fasting glucose concentrations than those in the lower quartiles. The plasma RBP4 levels showed a strong and positive correlation with triglycerides $(r=0.272, P<0.001)$. A higher plasma RBP4 was significantly correlated with both higher LDL cholesterol $(P<0.001)$ and lower HDL cholesterol $(P=0.004)$. No significant associations were observed for blood pressure. RBP4 was also significantly associated with elevated A-FABP levels $(r=0.104, P=0.001)$, but no correlation was observed between RBP4 and adiponectin $(r=0.030, P=0.151)$. In addition, RBP4 was strongly correlated with not only oxidative markers, such as 8-iso PGF2 $\alpha(r=0.236, P<0.001)$ and 13-HODE $(r=0.204$, $P<0.001)$, but also with elevated proinflammatory molecules, including hsCRP $(r=0.118, P=0.011)$, IL6 $(r=0.236, P<0.001), \mathrm{MCP} 1 \quad(r=0.145, P=0.005)$ and TNF $\alpha(r=0.187, P<0.001)$.

The RBP4 levels increased gradually with the number of MetS components (Figure 1). The RBP4 levels increased from $22.52 \mu \mathrm{g} / \mathrm{ml}$ in the participants with none of the MetS components up to $42.47 \mu \mathrm{g} / \mathrm{ml}$ in those with all 5 components. The OR $(95 \% \mathrm{CI})$ for MetS was 
Table 1 Characteristics of the study participants according to RBP4 quartiles



${ }^{1}$ Mean \pm SD (all such values).

${ }^{2}$ Includes coronary heart disease, stroke, hypertension, and diabetes in a parent or a first-degree sibling.

${ }^{3}$ Median (interquartile range).

$3.46(2.87,4.42)$ in the highest quartile of RBP4 compared with the lowest quartile, after controlling for age, sex, BMI, family history of chronic diseases and selfreported chronic diseases (Table 3). RBP4 was also positively associated with some of the MetS components, including hypertriglyceridemia, reduced HDL cholesterol, elevated LDL cholesterol and hyperglycemia. These associations were not materially attenuated by further adjustment of adipokines and oxidative and inflammatory markers.

\section{Discussion}

In the present study, we observed strong positive associations between plasma RBP4 concentrations and the increased risk of MetS and its components among middle-aged and elderly Chinese people. Furthermore, a chronic inflammatory response was significantly associated with higher plasma RBP4 levels, and the participants with those conditions were more likely to have higher RBP4 levels. Additionally, higher RBP4 levels were associated with oxidative stress, as reflected by a higher concentration of the oxidative markers.

RBP4, which is mainly secreted from adipocytes and hepatocytes, has been suggested to be a central regulator of insulin sensitivity. In animal models, the overexpression of human RBP4 or the injection of recombinant RBP4 induces insulin resistance in mice, whereas RBP4 knockout mice showed enhanced insulin sensitivity [23]. Our results suggest that high plasma RBP4 levels were associated with higher fasting glucose levels, $\mathrm{Hb}$ Alc and HOMA index, which was consistent with the animal studies. Furthermore, we also observed a positive 
Table 2 Multivariable-adjusted Spearman correlation coefficients of RBP4 and metabolic risk factors ${ }^{1}$

\begin{tabular}{lcc}
\hline & Spearman correlation coefficient & $\boldsymbol{P}$ \\
\hline BMI & 0.108 & 0.004 \\
Systolic blood pressure & 0.034 & 0.235 \\
Diastolic blood pressure & 0.042 & 0.189 \\
Fasting glucose & 0.095 & 0.018 \\
Insulin & 0.046 & 0.054 \\
HOMA-IR & 0.052 & 0.048 \\
Adiponectin & 0.030 & 0.151 \\
A-FABP & 0.104 & $<0.001$ \\
Total cholesterol & 0.139 & $<0.001$ \\
Triglycerides & 0.272 & $<0.001$ \\
HDL cholesterol & -0.072 & 0.004 \\
LDL cholesterol & 0.144 & $<0.001$ \\
8-iso PGF2a & 0.236 & $<0.001$ \\
13-HODE & 0.204 & $<0.001$ \\
hsCRP & 0.118 & 0.011 \\
IL6 & 0.236 & $<0.001$ \\
MCP1 & 0.145 & 0.005 \\
TNFa & 0.187 & $<0.001$ \\
\hline ISParman & & .
\end{tabular}

${ }^{1}$ Spearman correlation coefficients were adjusted by age, sex and BMI. A-FABP, adipocyte fatty acid-binding protein; 13-HODE, 8-iso PGF2a, 8-iso-prostaglandin F2a; 13-(S)-hydroxyoctadecadienoic acid (13-HODE); hsCRP, high sensitivity C-reactive protein; RBP-4, retinol-binding protein 4.

association between plasma RBP4 and total cholesterol, LDL cholesterol and triglycerides, but we observed an inverse correlation with HDL cholesterol concentrations in this population. We postulate that the effect of RBP4 on blood lipid concentrations, especially triglycerides, may be mediated through its effect on the metabolism of

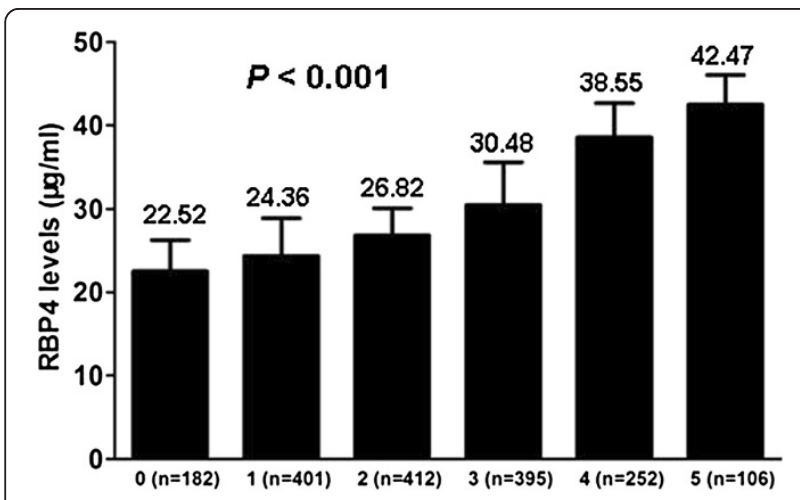

Figure 1 Plasma RBP4 concentrations according to the number of metabolic syndrome components. $P$ values were calculated from the multivariable-adjusted general linear regression model. The covariates adjusted included age, sex, drinking, smoking, family history of diabetes and cardiovascular diseases. hepatic fatty acids, which regulates the expression of genes involved in lipid metabolism [24].

In humans, several studies have also shown positive associations between RBP4 and insulin resistance as well as features of MetS [25,26]. However, several subsequent studies have failed to confirm these associations $[27,28]$. In the current study, we found positive associations of RBP4 with traditional metabolic traits and an increased risk of MetS presence. High levels of A-FABP and CRP and low levels of adiponectin are the well-documented risk factors for MetS and its components [29-31]. However, the relationship between RBP4 and A-FABP, CRP or adiponectin has not been well addressed because of the controversial reports. Balagopal et al. [32] reported that RBP4 was positively associated with CRP and negatively associated with adiponectin in a small group of obese children; however, no correlation between RBP4 and CRP or adiponectin was observed in another study of 101 hospitalized T2DM patients [33]. With a larger sample size, Qi Q [25] demonstrated a weak inverse correlation between RBP4 and adiponectin levels, but no correlation was detected between RBP4 and CRP levels. In this study, we indeed found a moderate inverse correlation between RBP4 and CRP levels, but no correlation was observed between RBP4 and adiponectin. Interestingly, we observed a positive association between RBP4 and A-FABP. RBP4 and A-FABP are two members of the lipocalin family, which are produced from mature adipocytes. We hypothesize that adipose tissues secrete these two adipocytokines via the same mechanism. More importantly, increased RBP4 per se was an independent risk factor for MetS, even within the lowest A-FABP or CRP quartile or the highest adiponectin quartile. Therefore, it is possible that RBP4 may promote MetS risk through a distinct pathway that does not fully overlap with F-FABP, CRP or adiponectin.

The obese condition and MetS are accompanied by low-grade chronic inflammation, which is characterized by an increased expression of inflammatory cytokines and infiltration of immune cells in adipocytes [34]. The inflammatory response promotes the activation of transcriptional factors and pro-inflammatory cytokines, which can lead to an unresolved inflammatory response associated with an inhibition of insulin signaling and a high risk for cardiovascular events [35]. In the present study, we observed a strong correlation between RBP4 levels and elevated inflammatory markers, including IL-6, MCP-1 and TNF- $\alpha$; this correlation has been well documented to play an important role in the initiation and development of inflammatory effects in adipose tissue. Thus, our results identified proinflammatory markers may be a critical link between RBP4 and the pathogenesis of MetS.

Accumulating evidence also supports the important role that oxidative stress plays in MetS-related manifestations 
Table 3 OR (and $95 \% \mathrm{Cl}$ ) of MetS and its components according to RBP4 quartiles ${ }^{1}$

\begin{tabular}{|c|c|c|c|c|c|}
\hline & \multicolumn{4}{|c|}{ RBP4 quartiles } & \multirow[b]{2}{*}{$P^{2}$} \\
\hline & 1 & 2 & 3 & 4 & \\
\hline Metabolic syndrome (no. cases) & 131 & 171 & 193 & 251 & \\
\hline Model $1^{3}$ & 1.00 & $1.65(1.29,1.99)$ & $2.28(1.76,2.89)$ & $3.84(3.12,4.58)$ & $<0.001$ \\
\hline Model $2^{4}$ & 1.00 & $1.61(1.26,1.97)$ & $2.15(1.65,2.73)$ & $3.46(2.87,4.42)$ & $<0.001$ \\
\hline Model $3^{5}$ & 1.00 & $1.53(1.21,1.92)$ & $2.04(1.58,2.47)$ & $2.68(1.95,3.67)$ & $<0.001$ \\
\hline Central obesity & 183 & 204 & 214 & 331 & \\
\hline Model 1 & 1.00 & $1.23(1.02,1.51)$ & $1.42(1.08,1.75)$ & $1.87(1.48,2.36)$ & $<0.001$ \\
\hline Model 2 & 1.00 & $1.01(0.74,1.32)$ & $0.97(0.67,1.28)$ & $0.92(0.66,1.35)$ & 0.69 \\
\hline Model 3 & 1.00 & $0.94(0.66,1.29)$ & $0.87(0.65,1.25)$ & $0.81(0.61,1.14)$ & 0.23 \\
\hline Hypertriglyceridemia & 46 & 77 & 112 & 197 & \\
\hline Model 1 & 1.00 & $2.13(1.64,2.87)$ & $3.45(2.61,4.49)$ & $6.75(5.28,8.96)$ & $<0.001$ \\
\hline Model 2 & 1.00 & $2.06(1.52,2.83)$ & $3.26(2.47,4.33)$ & $5.92(4.47,8.02)$ & $<0.001$ \\
\hline Model 3 & 1.00 & $1.97(1.46,2.68)$ & $3.01(2.16,4.08)$ & $5.03(3.59,7.45)$ & $<0.001$ \\
\hline Reduced HDL cholesterol & 154 & 171 & 177 & 186 & \\
\hline Model 1 & 1.00 & $1.24(1.05,1.51)$ & $1.38(1.15,1.67)$ & $1.76(1.26,2.17)$ & $<0.001$ \\
\hline Model 2 & 1.00 & $1.15(0.97,1.39)$ & $1.27(1.04,1.58)$ & $1.58(1.17,1.84)$ & $<0.001$ \\
\hline Model 3 & 1.00 & $1.07(0.90,1.26)$ & $1.18(0.96,1.51)$ & $1.42(1.11,1.68)$ & $<0.001$ \\
\hline Elevated blood pressure & 161 & 116 & 117 & 132 & \\
\hline Model 1 & 1.00 & $0.93(0.81,1.17)$ & $1.02(0.84,1.33)$ & $1.10(0.95,1.44)$ & 0.32 \\
\hline Model 2 & 1.00 & $0.87(0.76,1.15)$ & $0.97(0.81,1.24)$ & $1.02(0.84,1.29)$ & 0.11 \\
\hline Model 3 & 1.00 & $0.83(0.68,1.10)$ & $0.76(0.62,1.02)$ & $0.73(0.61,1.16)$ & 0.08 \\
\hline Hyperglycemia & 135 & 167 & 188 & 245 & \\
\hline Model 1 & 1.00 & $1.57(1.26,1.95)$ & $1.72(1.35,2.14)$ & $3.13(2.44,3.93)$ & $<0.001$ \\
\hline Model 2 & 1.00 & $1.50(1.17,1.84)$ & $1.67(1.31,1.96)$ & $2.74(2.15,3.36)$ & $<0.001$ \\
\hline Model 3 & 1.00 & $1.42(1.06,1.75)$ & $1.52(1.23,1.75)$ & $2.32(1.85,2.91)$ & $<0.001$ \\
\hline
\end{tabular}

${ }^{1}$ Metabolic syndrome was defined according to the updated National Cholesterol Education Program Adult Treatment Panel III criteria for Asian Americans.

${ }^{2}$ Calculated by using multivariable logistic regression.

${ }^{3}$ Adjusted for age and sex.

${ }^{4}$ Adjusted as for model 1 plus BMI (except when modeling associations for central obesity), smoking, drinking, family history of cardiovascular diseases and diabetes.

${ }^{5}$ Adjusted as for model 2 plus adiponectin, A-FABP, 8-iso PGF2a, 13-HODE, hsCRP, IL6, MCP1 and TNFa.

[36]. In this study, higher plasma RBP4 levels were significantly associated with higher serum 8-iso PGF2- $\alpha$ and 13-HODE, which suggests that a higher RBP4 status may contribute to oxidative damage. Both 8-iso PGF2- $\alpha$ and 13-HODE are major products of the peroxidation of unsaturated fatty acids and were shown to be reliable markers for oxidative stress $[37,38]$. Thus, the association of RBP4 with systematic oxidative stress markers in humans may explain the possible mechanism of a high RBP4 status on metabolic disorders in humans.

Several limitations of this study need to be addressed. First, the cross-sectional nature of the study design cannot be translated into a clear cause-effect inference. Prospective studies and randomized clinical trials are needed. Second, as with any observational study, the role of unmeasured or residual confounding cannot be ruled out; however, the multivariate models did adjust for a wide range of risk factors that have been implicated in the development of MetS or its individual components. Finally, we did not distinguish among full-length and truncated forms of RBP4 that might have various biological activities with potential varying effects on metabolic risk factors and MetS. Future studies with multiple measurements may substantiate our findings.

In conclusion, there was a strong positive association between plasma RBP4 with the risk of developing MetS in a middle-aged and elderly Chinese population: subjects with MetS or its components had a higher RBP4 status than those without these conditions. Moreover, the participants with high plasma RBP4 levels were also associated with the inflammatory markers and oxidative stress. Our results suggest a potential link between RBP4 and the incidence of MetS. 


\section{Abbreviations}

BMI: Body-mass index; Cl: Confidence intervals; CRP: High-sensitivity Creactive protein; CVD: Cardiovascular disease; HDL-C: High-density lipoprotein cholesterol; LDL-C: Low-density lipoprotein cholesterol; 8-iso PGF2a: 8-isoprostaglandin F2a; MetS: Metabolic syndrome; MCP1: Monocyte chemotactic protein-1; OR: Odds ratio; RBP4: Retinol-binding protein 4; TG: Triglyceride; T2DM: Type 2 diabetes mellitus; WHR: Waist-to-hip ratio.

\section{Competing interests}

The authors declare that they have no competing interests.

\section{Authors' contributions}

$Y L$ and DW conducted the research, performed the statistical analyses and wrote the manuscript; YL, DW and MW participated in the data collection and checked the data; and MX participated in the design of this study and wrote the manuscript. All authors have read and approved the final manuscript.

\section{Acknowledgements}

This study was supported by grants from the National Natural Science Foundation of China (No. 81072301) and the National Natural Science Foundation from Guangdong Province (No. S2012020011104). The project was supported by the Guangdong Province Universities and Colleges Funded Scheme (2011) and the Guangzhou City Science and Technology Project (12C22061588)

\section{Relationships with industry}

None of the authors have relationships with industry.

Received: 2 December 2013 Accepted: 18 February 2014

Published: 24 February 2014

\section{References}

1. Ford ES, Giles WH, Dietz WH: Prevalence of the metabolic syndrome among US adults: findings from the third National Health and Nutrition Examination Survey. JAMA 2002, 287:356-359.

2. Expert Panel on Detection, Evaluation, and Treatment of High Blood Cholesterol in Adults: Executive summary of the third report of the National Cholesterol Education Program (NCEP) expert panel on detection, evaluation, and treatment of high blood cholesterol in adults (adult treatment panel III). JAMA 2001, 285:2486-2497.

3. Eckel RH, Grundy SM, Zimmet PZ: The metabolic syndrome. Lancet 2005, 365:1415-1428.

4. Hee Park K, Zaichenko L, Brinkoetter M, Thakkar B, Sahin-Efe A, Joung KE, Tsoukas MA, Geladari EV, Huh JY, Dincer F, Davis CR, Crowell JA, Mantzoros CS: Circulating irisin in relation to insulin resistance and the metabolic syndrome. J Clin Endocrinol Metab 2013, 98:4899-4907.

5. Maury E, Noël L, Detry R, Brichard SM: In vitro hyperresponsiveness to tumor necrosis factor-alpha contributes to adipokine dysregulation in omental adipocytes of obese subjects. J Clin Endocrinol Metab 2009, 94:1393-1400.

6. Han TS, Sattar N, Williams K, Gonzalez-Villalpando C, Lean MEJ, Haffner SM: Prospective study of $\mathrm{C}$-reactive protein in relation to the development of diabetes and metabolic syndrome in the Mexico City Diabetes Study. Diabetes Care 2002, 25:2016-2021.

7. Furukawa S, Fujita T, Shimabukuro M, Iwaki M, Yamada Y, Nakajima Y, Nakayama O, Makishima M, Matsuda M, Shimomura I: Increased oxidative stress in obesity and its impact on metabolic syndrome. J Clin Invest 2004, 114:1752-1761.

8. Blaner WS: Retinol-binding protein: the serum transport protein for vitamin A. Endocr Rev 1989, 10:308-316.

9. Graham TE, Yang Q, Blüher M, Hammarstedt A, Ciaraldi TP, Henry RR, Wason C, Oberbach A, Jansson PA, Smith U, Kahn BB: Retinol-binding protein 4 and insulin resistance in lean, obese, and diabetic subjects. N Engl J Med 2006, 354:2552-2563.

10. Norseen J, Hosooka T, Hammarstedt A, Yore MM, Kant S, Aryal P, Kiernan UA, Phillips DA, Maruyama H, Kraus BJ, Usheva A, Davis RJ, Smith U, Kahn BB: Retinol-binding protein 4 inhibits insulin signaling in adipocytes by inducing proinflammatory cytokines in macrophages through a c-Jun $\mathrm{N}$-terminal kinase- and toll-like receptor 4-dependent and retinolindependent mechanism. Mol Cell Bio/ 2012, 32:2010-2019.
11. Klöting N, Graham TE, Berndt J, Kralisch S, Kovacs P, Wason CJ, Fasshauer M, Schön MR, Stumvoll M, Blüher M, Kahn BB: Serum retinol-binding protein is more highly expressed in visceral than in subcutaneous adipose tissue and is a marker of intra-abdominal fat mass. Cell Metab 2007, 6:79-87.

12. Tschoner A, Sturm W, Engl J, Kaser S, Laimer M, Laimer E, Weiss H, Patsch JR, Ebenbichler CF: Retinol-binding protein 4, visceral fat, and the metabolic syndrome: effects of weight loss. Obesity (Silver Spring) 2008 16:2439-2444

13. Ng TW, Watts GF, Barrett PH, Rye KA, Chan DC: Effect of weight loss on LDL and HDL kinetics in the metabolic syndrome: associations with changes in plasma retinol-binding protein-4 and adiponectin levels. Diabetes Care 2007, 30:2945-2950.

14. Ingelsson E, Sundström J, Melhus H, Michaëlsson $K$, Berne C, Vasan RS, Risérus $U$, Blomhoff R, Lind L, Arnlöv J: Circulating retinol-binding protein 4, cardiovascular risk factors and prevalent cardiovascular disease in elderly. Atherosclerosis 2009, 206:239-244.

15. Sun Q, Kiernan UA, Shi L, Phillips DA, Kahn BB, Hu FB, Manson JE, Albert CM, Rexrode KM: Plasma retinol-binding protein 4 (RBP4) levels and risk of coronary heart disease: a prospective analysis among women in the nurses' health study. Circulation 2013, 127:1938-1947.

16. Cho YM, Youn BS, Lee H, Lee N, Min SS, Kwak SH, Lee HK, Park KS: Plasma retinol-binding protein-4 concentrations are elevated in human subjects with impaired glucose tolerance and type 2 diabetes. Diabetes Care 2006, 29:2457-2461.

17. Chavez AO, Coletta DK, Kamath S, Cromack DT, Monroy A, Folli F, DeFronzo RA, Tripathy D: Retinol-binding protein 4 is associated with impaired glucose tolerance but not with whole body or hepatic insulin resistance in Mexican Americans. Am J Physiol Endocrinol Metab 2009, 296:E758-E764.

18. Kotnik P, Fischer-Posovszky P, Wabitsch M: RBP4-a controversial adipokine. Eur J Endocrinol 2011, 165:703-711.

19. Promintzer $M$, Krebs M, Todoric J, Luger A, Bischof MG, Nowotny $P$, Wagner $O$, Esterbauer $\mathrm{H}$, Anderwald $\mathrm{C}$ : Insulin resistance is unrelated to circulating retinol binding protein and protein C inhibitor. J Clin Endocrinol Metab 2007, 92:4306-4343. sss 12

20. Graham TE, Wason CJ, Bluher M, Kahn BB: Shortcomings in methodology complicate measurements of serum retinol binding protein (RBP4) in insulin-resistant human subjects. Diabetologia 2007, 50:814-823.

21. Friedewald WT, Levy RI, Fredrickson DS: Estimation of the concentration of low-density lipoprotein cholesterol in plasma, without use of the preparative ultracentrifuge. Clin Chem 1972, 18:499-502.

22. Grundy SM, Cleeman JI, Daniels SR, Donato KA, Eckel RH, Franklin BA, Gordon DJ, Krauss RM, Savage PJ, Smith SC Jr, Spertus JA, Costa F: Diagnosis and management of the metabolic syndrome: an American Heart Association/National Heart, Lung, and Blood Institute Scientific Statement. Circulation 2005, 112:2735-2752.

23. Yang Q, Graham TE, Mody N, Preitner F, Peroni OD, Zabolotny JM, Kotani K, Quadro L, Kahn BB: Serum retinol binding protein 4 contributes to insulin resistance in obesity and type 2 diabetes. Nature 2005, 436:356-362.

24. Xia M, Liu Y, Guo H, Wang D, Wang Y, Ling W: Retinol binding protein 4 stimulates hepatic sterol regulatory element-binding protein 1 and increases lipogenesis through the peroxisome proliferator-activated receptor- $\gamma$ coactivator $1 \beta$-dependent pathway. Hepatology 2013, 58:564-575.

25. Qi Q, Yu Z, Ye X, Zhao F, Huang P, Hu FB, Franco OH, Wang J, Li H, Liu Y, Lin $X$ : Elevated retinol-binding protein 4 levels are associated with metabolic syndrome in Chinese people. J Clin Endocrinol Metab 2007, 92:4827-4834

26. Hammarstedt A, Graham TE, Kahn BB: Adipose tissue dysregulation and reduced insulin sensitivity in non-obese individuals with enlarged abdominal adipose cells. Diabetol Metab Syndr 2012, 4:42.

27. Takashima N, Tomoike H, Iwai N: Retinol-binding protessin 4 and insulin resistance. N Engl J Med 2006, 355:1392. author reply 1394-139s5.

28. Janke J, Engeli S, Boschmann M, Adams F, Böhnke J, Luft FC, Sharma AM, Jordan J: Retinol-binding protein 4 in human obesity. Diabetes 2006 , 55:2805-2810.

29. Matsuzawa Y, Funahashi T, Kihara S, Shimomura I: Adiponectin and metabolic syndrome. Arterioscler Thromb Vasc Biol 2004, 24:29-33.

30. Xu A, Tso AW, Cheung BM, Wang Y, Wat NM, Fong CH, Yeung DC, Janus ED, Sham PC, Lam KS: Circulating adipocyte-fatty acid binding protein levels predict the development of the metabolic syndrome: a 5-year prospective study. Circulation 2007, 115:1537-1543. 
31. Ye X, Yu Z, Li H, Franco OH, Liu Y, Lin X: Distributions of C-reactive protein and its association with metabolic syndrome in middle-aged and older Chinese people. J Am Coll Cardiol 2007, 49:1798-1805.

32. Balagopal P, Graham TE, Kahn BB, Altomare A, Funanage V, George D: Reduction of elevated serum retinol binding protein in obese children by lifestyle intervention: association with subclinical inflammation. J Clin Endocrinol Metab 2007, 92:1971-1974.

33. Takebayashi K, Suetsugu M, Wakabayashi S, Aso Y, Inukai T: Retinol binding protein-4 levels and clinical features of type 2 diabetes patients. $J$ Clin Endocrinol Metab 2007, 92:2712-2719.

34. Sell $\mathrm{H}$, Habich C, Eckel J: Adaptive immunity in obesity and insulin resistance. Nat Rev Endocrinol 2012, 8:709-716.

35. Romeo GR, Lee J, Shoelson SE: Metabolic syndrome, insulin resistance, and roles of inflammation-mechanisms and therapeutic targets. Arterioscler Thromb Vasc Biol 2012, 32:1771-1776.

36. Elnakish MT, Hassanain HH, Janssen PM, Angelos MG, Khan M: Emerging role of oxidative stress in metabolic syndrome and cardiovascular diseases: important role of Rac/NADPH oxidase. J Pathol 2013, 231:290-300.

37. Pratico D: $F(2)$-isoprostanes: sensitive and specific non-invasive indices of lipid peroxidation in vivo. Atherosclerosis 1999, 147:1-10.

38. Vangaveti V, Baune BT, Kennedy RL: Hydroxyoctadecadienoic acids: novel regulators of macrophage differentiation and atherogenesis. Ther Adv Endocrinol Metab 2010, 1:51-60.

doi:10.1186/1758-5996-6-25

Cite this article as: Liu et al:: Associations of retinol-binding protein 4 with oxidative stress, inflammatory markers, and metabolic syndrome in a middle-aged and elderly Chinese population. Diabetology \& Metabolic Syndrome 2014 6:25.

\section{Submit your next manuscript to BioMed Central and take full advantage of:}

- Convenient online submission

- Thorough peer review

- No space constraints or color figure charges

- Immediate publication on acceptance

- Inclusion in PubMed, CAS, Scopus and Google Scholar

- Research which is freely available for redistribution 